\title{
Voiding dysfunction in patients with spinal cord lesions at the thoraco- lumbar vertebral junction
}

\author{
F Pesce, V Castellano, E Finazzi Agrò, A Giannantoni, F Tamburro, G Vespasiani \\ Department of Urology, University Tor Vergata and S. Lucia Rehabilitation Hospital IRCCS, Rome, Italy
}

\begin{abstract}
Neurogenic voiding dysfunction invariably follows a complete spinal cord lesion. With spinal shock urodynamic investigation will show an areflexic bladder if the sacral spinal cord has been damaged, otherwise, if the lesion involves the suprasacral cord, an overactive bladder will result. There are some exceptions to this rule, particularly in those with lesions of the thoracolumbar vertebral junction, where the sacral cord is located, it may be difficult to predict urodynamic dysfunction merely on the basis of the vertebral body involved. 46 patients with a complete SCI neurological lesion at the thoraco-lumbar vertebral junction underwent a neurourological evaluation including multi-channel urodynamic studies. Overall in 20 to $36 \%$ of the patients the urodynamic pattern was different from what one would have expected considering the anatomical level of the vertebral body involved. Urodynamic study is confirmed as an essential tool in the correct diagnostic and therapeutic approach to the voiding dysfunction in these type of patients.
\end{abstract}

Keywords: Spinal cord injury; neurogenic voiding dysfunction; Urodynamics; upper and lower motor neuron lesions

\section{Introduction}

A spinal cord injury (SCI), even if incomplete, almost invariably causes substantial changes in detrusor and in perineal floor behaviour, during both the urinary storage and emptying phases. These micturition abnormalities may vary according to the level of the cord lesion and to its completeness and extension., The cord level is important mainly in relation to the involvement of the sacral segments $(\mathrm{S} 2, \mathrm{~S} 3, \mathrm{~S} 4$, or conus medullaris), where both the sacral parasympathetic nucleus and the pudendal nucleus (Onuf's nucleus) are located. In fact, the common belief ${ }^{3}$ is that lesions which involve the spinal cord cranial to the conus (supra-nuclear lesions, defined in the past as 'upper motor-neuron' lesions) ${ }^{4}$ determine detrusor hyperreflexia $(\mathrm{DH})$, associated in most instances with detrusor-sphincter dyssynergia (DSD); alternatively, lesions at the conus or cauda level (nuclear or 'lower motor-neuron' lesions) determine detrusor areflexia (DA), generally associated with denervation of the perineal floor. This is not always a hard-and-fast rule, as there are situations in which the vesico-sphincter complex does not behave in the manner described above, ${ }^{5,6}$ particularly when the lesion is located at the thoraco-lumbar vertebral level, ${ }^{3}$ as the conus medullaris usually corresponds to the vertebral bodies T12 and L1.

Correspondence: F Pesce

*In this paper all methods, definitions and units conform to the standards proposed by the International Continence Society ${ }^{7}$ except where specifically noted.
This retrospective study was aimed at analysing the variability of the type of neurogenic voiding dysfunction in patients with vertebral lesions of the junction between the thoracic and lumbar vertebral tract, which corresponds to the medullar cone (S2-S4 spinal cord level, site of the detrusor and pudendal nuclei).

\section{Materials and methods}

170 Spinal cord injured patients were evaluated in the Neuro-Urology Section of the S. Lucia Rehabilitation Hospital from February 1993 to June 1995. We retrospectively reviewed 46 SCI patients with vertebral lesions between $\mathrm{T} 11$ and $\mathrm{L} 2$; all of the patients were paraplegic, with 'complete' neurological lesions, and were clearly beyond the spinal shock period (established post-injury phase). 36 were males, 10 females (average age $40 \pm 13$ years, range $14-70$ years. The vertebral bodies involved were single in 33 patients, multiple ( 2 or 3 bodies) in 13 patients (Figure 1 ). The average interval between the time of the SCI and the neuro-urological evaluation was $112 \pm 125$ months (range 1 month-30 years. All the patients were studied with neuro-urologically oriented history, neuro-urological physical examination and urodynamic evaluation*. The latter was accomplished by means of multi-channel studies, with recording of bladder, rectal and subtracted detrusor pressures, and concentric needle electromyography of the perineal floor. The concentric needle EMG electrode was inserted into the right bulbo-cavernosous muscle in 
men, and in the external anal sphincter (12 o'clock position) in women. The exactness of needle insertion was confirmed by the sound emanating from a loudspeaker connected to the EMG amplifier. A double lumen $8 \mathrm{~F}$ catheter was used to record vesical pressure and to perform filling cystometry. The bladder

Table 1 Results of Urodynamic investigations in 46 consecutive patients with SCI at the thoraco-lumbar passage level. Sex, age, vertebral bodies injured and interval from the injury are also shown for each patient

\begin{tabular}{|c|c|c|c|c|c|}
\hline No. & Sex & $\begin{array}{l}\text { Age } \\
\text { (yrs.) }\end{array}$ & $\begin{array}{c}\text { Lesional } \\
\text { level }\end{array}$ & $\begin{array}{c}\text { Interval } \\
\text { (mos.) }\end{array}$ & $U D M^{*}$ \\
\hline 1 & $\mathrm{~F}$ & 31 & $\mathrm{~T} 12$ & 13 & $\mathrm{DH}+\mathrm{DSD}$ \\
\hline 2 & M & 50 & $\mathrm{~T} 11-\mathrm{T} 12$ & 262 & $\mathrm{DH}+\mathrm{DSD}$ \\
\hline 3 & M & 30 & T12 & 62 & DH \\
\hline 4 & M & 38 & $\mathrm{~T} 12$ & 6 & $\mathrm{DH}$ \\
\hline 5 & M & 59 & $\mathrm{~T} 12$ & 240 & $\mathrm{DH}+\mathrm{DSD}$ \\
\hline 6 & M & 46 & $\mathrm{~T} 12$ & 168 & $\mathrm{DH}+\mathrm{DSD}$ \\
\hline 7 & M & 24 & L1 & 48 & $\mathrm{DH}+\mathrm{DSD}$ \\
\hline 8 & M & 45 & L1 & 144 & $\mathrm{DH}+\mathrm{DSD}$ \\
\hline 9 & $\mathrm{~F}$ & 43 & $\mathrm{~T} 12$ & 240 & DH \\
\hline 10 & M & 42 & $\mathrm{~T} 12$ & 156 & DA \\
\hline 11 & M & 70 & L1 & 362 & DA \\
\hline 12 & M & 35 & $\mathrm{~T} 12-\mathrm{L} 1$ & 4 & DA \\
\hline 13 & M & 50 & $\mathrm{~T} 12-\mathrm{L} 1$ & 180 & DH \\
\hline 14 & M & 53 & T12 & 384 & DH \\
\hline 15 & M & 45 & $\mathrm{~T} 12$ & 266 & DA \\
\hline 16 & M & 22 & $\mathrm{~T} 12$ & 1 & $\mathrm{DH}+\mathrm{DSD}$ \\
\hline 17 & M & 57 & T12-L1 & 228 & $\mathrm{DH}+\mathrm{DSD}$ \\
\hline 18 & $\mathrm{~F}$ & 46 & T11 & 1 & $\mathrm{DH}+\mathrm{DSD}$ \\
\hline 19 & $\mathrm{~F}$ & 32 & $\mathrm{~T} 11-\mathrm{T} 12$ & 12 & DA \\
\hline 20 & $\mathrm{~F}$ & 25 & L1 & 18 & DA \\
\hline 21 & M & 41 & L1 & 300 & DA \\
\hline 22 & M & 22 & $\mathrm{~T} 12-\mathrm{L} 2$ & 52 & DA \\
\hline 23 & M & 14 & T12 & 5 & DA \\
\hline 24 & M & 36 & T12 & 166 & DA \\
\hline 25 & M & 44 & $\mathrm{~T} 12-\mathrm{L} 1$ & 274 & $\mathrm{DH}+\mathrm{DSD}$ \\
\hline 26 & M & 23 & L1 & 17 & DA \\
\hline 27 & M & 26 & $\mathrm{~T} 11-\mathrm{T} 12$ & 38 & DA \\
\hline 28 & $\mathrm{~F}$ & 30 & $\mathrm{~T} 12-\mathrm{L} 1$ & 234 & $\mathrm{DH}+\mathrm{DSD}$ \\
\hline 29 & M & 29 & $\mathrm{~T} 12-\mathrm{L} 1$ & 35 & DH \\
\hline 30 & M & 40 & $\mathrm{~T} 12-\mathrm{L} 1$ & 156 & $\mathrm{DH}+\mathrm{DSD}$ \\
\hline 31 & $\mathrm{~F}$ & 35 & $\mathrm{~L} 1-\mathrm{L} 2$ & 41 & DA \\
\hline 32 & $\mathrm{~F}$ & 60 & L2 & 3 & $\mathrm{DH}+\mathrm{DSD}$ \\
\hline 33 & M & 23 & $\mathrm{~T} 12-\mathrm{L} 1$ & 12 & DA \\
\hline 34 & M & 44 & T12 & 276 & $\mathrm{DH}+\mathrm{DSD}$ \\
\hline 35 & M & 32 & L1 & 12 & DA \\
\hline 36 & M & 64 & L1 & 5 & DA \\
\hline 37 & M & 24 & L1 & 37 & DA \\
\hline 38 & M & 27 & $\mathrm{~T} 11$ & 2 & DH \\
\hline 39 & M & 35 & $\mathrm{~T} 12$ & 2 & DA \\
\hline 40 & $\mathrm{~F}$ & 37 & L1 & 4 & DA \\
\hline 41 & $\mathrm{~F}$ & 34 & $\mathrm{~T} 11$ & 14 & $\mathrm{DH}+\mathrm{DSD}$ \\
\hline 42 & M & 57 & L1 & 48 & DA \\
\hline 43 & M & 67 & L1 & 88 & DA \\
\hline 44 & M & 57 & L1 & 15 & DA \\
\hline 45 & M & 62 & $\mathrm{~T} 12$ & 463 & DA \\
\hline 46 & M & 35 & T12 & 60 & $\mathrm{DH}+\mathrm{DSD}$ \\
\hline
\end{tabular}

was filled with normal saline at room temperature, with an infusion rate of $50 \mathrm{ml} / \mathrm{min}$. A water-filled balloon catheter $(12 \mathrm{~F})$ was used to record the rectal pressure. Both the vesical and rectal pressures were measured with external transducers positioned at the symphysis pubis level. During filling cystometry the following parameters were recorded: the presence, threshold and maximum pressure of uninhibited detrusor contractions (Detrusor Hyperreflexia, DH), the maximum cystometric capacity, the presence of pelvic floor contractions during detrusor contraction (Detrusor-Sphincter Dyssynergia, DSD), the detrusor compliance (measured in $\mathrm{ml} / \mathrm{cmH} 2 \mathrm{O}$ ). The failure to achieve a voluntary or reflex detrusor contraction was regarded as Detrusor Areflexia (DA).

\section{Results}

Urodynamic diagnosis

The results of the urodynamic investigations in this study population are shown in Table 1 . Overall, in $50 \%$ of the patients (23 patients) the urodynamic diagnosis was detrusor areflexia. Of the 23 patients with detrusor hyperrflexia, 16 also had detrusor/sphincter dyssynergia. In particular, of the 22 patients with vertebral lesions above L1 (where the medullar cone is usually located), eight patients $(36 \%)$ showed detrusor areflexia and 14 detrusor hyperreflexia, of whom nine also demonstrated detrusor/sphincter dyssynergia. Of the 15 patients with a lesion involving L1 or a lower vertebral body, three patients $(20 \%)$ showed DH and DSD. Of nine patients with a lesion of T12 and L1, three showed DA and six $\mathrm{DH}$, of whom four with DSD.

\section{Neuro-Urological physical examination}

There was a good correlation between the presence of clinical signs of perineal floor denervation, and the presence of detrusor areflexia: in fact, in $22 / 23$ patients with DA the $\mathrm{BC}$ reflex could not be elicited.

Uninhibited contractions (UHC)

In the 23 patients with $\mathrm{DH}$ the UHCs had a threshold of $210 \pm 152 \mathrm{ml}$ (mean \pm standard deviation), with a range of $40-650 \mathrm{ml}$. The UHCs reached a mean maximum pressure of $90 \pm 54 \mathrm{cmH}_{2} \mathrm{O}$ (range: $40-$ $250 \mathrm{cmH}_{2} \mathrm{O}$ ).

\section{Maximum cystometric capacity}

In the whole study population the maximum cystometric capacity was $410 \pm 205 \mathrm{ml}$ (range: $70-900 \mathrm{ml}$ ).

\section{Detrusor compliance}

Varying degrees of low detrusor compliance $(<30 \mathrm{ml} /$ $\mathrm{cmH}_{2} \mathrm{O}$ ) were found in $4 / 46$ patients: in all cases the urodynamic diagnosis was DA. 


\section{Discussion}

Following a spinal cord injury, profound changes usually take place in the behaviour of the lower urinary tract. The type of vesico-urethral dysfunction depends essentially on the site of the cord lesion and on its extension. As a general rule, if the lesion involves the spinal cord above the sacral segments, it leaves unaffected the sacral micturition centre (parasympathetic and somatic). The latter is not inhibited any longer by the pontine micturiction centre, and an overactive bladder results (detrusor hyperreflexia). In most patients the synergistic mechanism enabling complete relaxation of the pelvic floor during a bladder contraction is also lost (detrusor-sphincter dyssynergia). On the other end, if the lesion involves the sacral micturition centre, the usual urodynamic pattern is characterised by an acontractile bladder (detrusor areflexia) with varying degrees of perineal floor denervation. A neurogenic decrease in bladder compliance is also quite common.

The conus medullaris of the cord in the adult subject usually corresponds to the vertebral bodies T12 and L1, therefore one would expect that traumatic lesions involving these vertebrae always lead to a lower motor neuron type of vesico-urethral dysfunction, and lesions above that vertebral level are followed by an upper motor neuron type of dysfunction. However, in clinical practice it is not difficult to observe patients where this rule is not applicable. Several hypotheses have been advocated to explain this phenomenon, including coexistence of a second sub-clinical lesion at a different level, a posttraumatic vascular involvement of distal spinal segments, a variability in cord-to column correlation, and myogenic detrusor damage due to bladder overdistension.

This study confirmed the possibility of 'unexpected' vesico-sphincter behaviour in about $30 \%$ of the population studied. In fact, $36 \%$ of the patients with a vertebral level above L1 showed an areflexic bladder and $20 \%$ of the patients with a lesion at L1 vertebral level or lower showed detrusor hyperreflexia with DSD. The sub-group of nine patients with a lesion of both $\mathrm{T} 12$ and $\mathrm{L} 1$ included three patient (33\%) with DA and six patients $(66 \%)$ with DH (four with DSD).

In these patients we could not find a definite explanation to justify the lack of correlation between the vertebral level of the lesion and the voiding dysfunction. The good correlation between the clinical evaluation of the perineal floor integrity and the bladder behaviour tends to exclude a myogenic detrusor failure as a cause of bladder acontractility in this sub-group of patients. Unfortunately we did not have the opportunity to examine the MR films for the majority of the patients: we believe that such information could provide useful data at least in some instances.

In conclusion, the evaluation of voiding dysfunction associated with SCI involving the thoraco-lumbar junction, it is difficult to predict the urodynamic pattern exclusively on the basis of the lesional level and the physical neurological examination. This confirms the necessity for urodynamic investigation for effective diagnostic and therapeutic approach for such patients.

\section{References}

1 Yalla SV, Rossier AB, Fam BA: Dyssynergic vesicourethral responses during bladder rehabilitation. J Urol 1976; 115: 575.

2 Fam BA, Rossier AB, Blunt K et al: Experience in the urologic management of 120 early spinal cord injury patients. J Urol 1978; 119: 485.

3 Sullivan M, Yalla SV: Spinal cord injury and other forms of myeloneuropathies. Problems in Urology 1992; 6(4): 643.

4 Bors E, Comarr AE: Neurological Urology. Baltimore: University Park Press, 1971.

5 Kaplan AS, Chancellor MB, Blaivas JG: Bladder and sphincter behavior in patients with spinal cord lesions. J Urol 1991; 146: 113.

6 Light JK, Faganal J, Beric A: Detrusor areflexia in supraspinal cord injuries. J Urol 1985; 134: 295.

7 Abrams P, Blaivas JG, Stanton SL, Anderson JT. The standardisation of terminology of lower urinary tract function. Neurourol Urodyn 1988; 7: 403. 